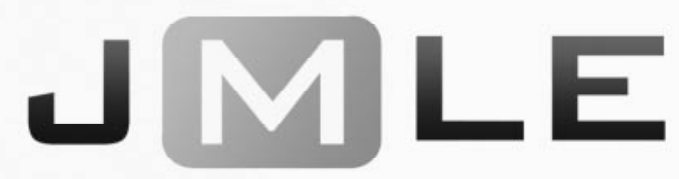

The National Association for Media Literacy Education's

Journal of Media Literacy Education 1 (2009) 81-82

Professional Resource:

\title{
Code of Best Practices in Fair Use For Media Literacy Education (2008)
}

\section{Chris Boulton}

Department of Communication, University of Massachusetts, Amherst, MA, USA

Code of Best Practices in Fair Use or Media Literacy Education, (2008).

http://www.centerforsocialmedia.org/resources/publications/code_for_media_literacy_education/

New media and communication technologies have expanded both our object of study and the range of techniques for teaching our students, but powerful gatekeepers remain. From corporate owners crying foul when we quote from copyrighted material to school administrators haunted by the specter of lawsuits, a culture of fear has descended over teaching in the digital age, bombarding us with a myriad of confusing guidelines and dubious restrictions. Some have pushed back, arguing that our right to access and produce media in educational settings is protected by the doctrine of "fair use" as outlined in Section 107 of the Copyright Act of 1976. But the rest of us play it safe and simply avoid using any media that might get us into trouble. The Code of Best Practices in Fair Use or Media Literacy Education (herein referred to simply as "the code") takes aim at this kind of selfcensorship. ${ }^{1}$ Best of all, it is quite readable, avoiding jargon in favor of concrete examples of classroom practices - the kind of document you could easily pull out to calm skittish colleagues and supervisors. The code itself is concise and freely available online so I will not attempt to summarize it here. Instead, I will seek to provide some context, emphasize the code's central themes, and then make an argument for why it should be implemented widely.

The code joins a collection of grassroots campaigns already in progress. For example, the Society for Cinema and Media Studies (SCMS) recently published a Statement of Best Practices for Fair Use in Teaching for Film and Media Educators based on a survey of practitioners and emphasizing a hard-fought legal exemption allowing educators to hack copy-protected DVD's copies for classroom use. ${ }^{2}$ The Center for Social Media has also produced several reports and statements on fair use for producers of media content that seek to strike a healthy balance between intellectual property and creative freedom. There is even a movement afoot among members of the International Communication Association (ICA) to query the membership and produce a collective statement on the rights and responsibilities of fair use for communication scholars. In similar fashion, this code began with a series of meetings with over 150 media educators and advocates in ten cities all over the United States. The resulting consensus around commonly held understandings was then vetted by a committee of legal scholars and endorsed by leading media literacy organizations. Such a "bottom-up" approach not only exemplifies a democratic and participatory process of deliberation but also helped forge a set of principles that are relevant, practical, and clear to the stakeholders who would implement them.

The Code's five principles apply across media forms (from newspapers to YouTube) and educational settings (from schools to non-profits). So, if you wish to copy a movie clip for class, you can disregard that scary FBI warning providing that you follow the "rule of proportionality." In other words - and this a central theme of the code-only use what you need to accomplish your curricular goals. Depending on the lesson, this could range from a short excerpt to the entire work. Such flexibility emphasizes how fair use can vary according to context and situation. Another central theme in the code concerns whether the use 
transforms, repurposes, and/or adds value to the copyrighted material. If it does, then it's probably fair. ${ }^{3}$

For each of the five principles, the code outlines a set of related instructional activities and then states both the rights and limitations of fair use. And while the first three focus on fair use from the perspective of educators - 1) teaching, 2) preparing curriculum, and 3) sharing resources - the last two consider the 4) production and 5) distribution of student work. This move illustrates how the concept of fair use can cover both the pedagogy of media critique and the process of media production. Thus, while the code could inspire an instructor to show clips that demonstrate the commercial nature of powerful media institutions, it could also encourage students to sample and re-edit those same clips to tell a different story. ${ }^{4}$ For instance, Matthew Soar and his students at Concordia University used animation to transform and add value to an existing concert video of Girl Talk - an artist who himself claims fair use when remixing hundreds of samples from copyrighted songs.

The code insists that "the social bargain at the heart of copyright law" grants "limited property rights" as an incentive for generating culture but also adds the important caveat of fair use that can allow that same property to be used by still other creators, without permission or payment, to generate new culture. ${ }^{5}$ Thus, fair use promotes a dynamic atmosphere where culture remains in a constant cycle of transformation-every remix inventing potential ingredients for the next. In this way, "fair use keeps copyright from violating the First Amendment." $"$ The current dearth of legal precedent means that educators have an opportunity to influence both current practice and emerging policy by openly and publicly asserting their right to transform copyrighted material. In anticipation of potential obstacles to this effort, the code concludes by dispelling some of the common myths around fair use that characterize it as: a) too complicated, b) subject to iron-clad "rules of thumb;" c) only for critical commentary; d) only for noncommercial work; e) a big hassle with lots of paperwork; f) and just plain risky. "Nonsense!" cries the code. Fair use is a right, not a defense, and its flexibility makes it adaptable to rapid technological change.

Here is the take-home message: if the use is transformative and proportional, then unlicensed copyrighted material is fair game for both teachers and students either inside or outside the classroom. In other words, this code argues that the remixing of culture in educational settings is not only perfectly legal but can even be done for fun and/or profit. No one has been sued for this yet and as more teachers exercise and loudly proclaim their fair use rights, the already remote possibility of a lawsuit will simply fade into distant memory as a ghost of copyright's past. The Code of Best Practices in Fair Use for Media Literacy Education is on the right side of history and its wide application will hasten a better future for us all.

\section{Notes}

${ }^{1}$ Code of Best Practices in Fair Use or Media Literacy Education, (2008). Retrieved May 25, 2009, from http://www.centerforsocialmedia.org/resources/publications/code_for_media_literacy_education/

${ }^{2}$ This exemption to the Digital Millennium Copyright Act (DMCA) was spearheaded by Peter Decherney and Katherine Sender at UPenn. For more details, go here.

${ }^{3}$ For a wonderful three minute illustration of the central questions for determining fair use, check out Michael RobbGrieco's “User Rights, Section 107 Music Video."

${ }^{4}$ In 1991, fair use pioneer Sut Jhally began selling a video critiquing the sexist tropes of music videos and MTV threatened to sue him for copyright infringement. Jhally stood his ground and founded the Media Education Foundation soon after MTV caved.

${ }^{5}$ Code of Best Practices in Fair Use or Media Literacy Education: 5.

${ }^{6}$ Ibid. 